\title{
Implementation of a bang-bang strategy for PV system connected to the grid
}

\author{
B. Efker $^{(1)}$, A. Martinez ${ }^{(2)}$, H.M. Reddy ${ }^{(3)}$ \\ (1) Siemens AG - Osnabrück, GERMANY \\ ${ }^{(2)}$ Ecole d’Ingénieurs en Génie des Systèmes Industriels (EIGSI), La Rochelle, FRANCE \\ ${ }^{(3)}$ School of Engineering, University of the South Pacific , Suva, FIJI ISLANDS.
}

\begin{abstract}
This paper presents a bang-bang strategy for PV system connected to the grid. A string PV system coupled to a single stage inverter is described. The inverter presented in this paper utilizes higher order DC filtering and is made of a single stage topology utilizing PI regulators to control the Maximum Power Point (MPP). Additional PI regulators are employed to minimize the Total Harmonic Distorsion (THD) to the minimum. The inverter designed meets all relevant standards requirements.
\end{abstract}

\section{INTRODUCTION}

The current focus on alternative and renewable energy sources has seen development of power system as distributed generation system and it is predicted to be the common topology to be seen in future [1], [2]. Within the distributed power system, photovoltaic (PV) system is considered to become one of the major energy sources in the future [1]-[5]. The key technology to improve the performance of photovoltaic systems is intelligent command through feedback, and efficacy in power regulation [5].

The PV system configuration is a "string" technology as described by [9]. A higher generating voltage of $450 \mathrm{~V}$ is used for grid connected system in order to develop a plant with higher voltage and power levels.

Since experimentations on hardware being relatively expensive, the latest computing tools is considered to be a better alternative to simulate the outcomes of such expensive systems as the PV system. The PV system's efficiency is evaluated for different command techniques particularly for the inverter. An investigation is conducted for one of the major constraints in the utility interactive PV system, the total harmonic distortion THD caused by the different command strategies.

The first step was to develop a model of photovoltaic installations, including all relevant parameters and models. The modeling of the PV array was done based on equations of semiconductor physics and the mathematical description of the solar and power curve of a PV array. Furthermore, the intension was to keep the model flexible such that the external influences such as solar irradiation and temperature, parameters of the solar cell for example off load voltage, short circuit current, PV array's size etc. can be changed to adopt the model for different conditions rapidly. The main intent, in this paper, is to study the performance of a single stage inverter model designed for PV application.

\section{PV System Model ARChitecture}

Due to PV systems costs, the inverter must be economically designed to reach low price in the market and to accelerate the development of renewable energy power plants. In any case, it must adhere to the standards adopted by various regions [6]-[8] and utility demands for grid interactive inverters.

The inverter model developed is a $1.2 \mathrm{~kW}$, transformerless inverter for grid connected PV installation. The use of transformerless inverters has its own advantages and limitations. Its key advantages are higher efficiency, and reduced form factor and weight making it economical compared to topologies where transformers are employed [5], [9].

But on the other side, if the design is not robust, transformerless inverters are known to cause electromagnetic interferences (EMI). A requirement of such topology is the PV array's output voltage must be greater than the peak voltage of public mains [3], [5]. This topology also raises the issue of non availability of galvanic isolation.

\section{A. Standard Test Conditions (STC)}

To ensure equal test conditions, the conditions stayed as follows:

- $\quad$ Solar cell's temperature: $25^{\circ} \mathrm{C}$.

- Solar irradiation: $\mathrm{G}=1000 \mathrm{~W} / \mathrm{m}^{2}$

- PV array’s off-load (open-loop) voltage: $450 \mathrm{~V}$

- PV array's short circuit current: $3.8 \mathrm{~A}$

- PV array's material: Crystalline Silicon

- PV array's size: $10 \mathrm{~m}^{2}$

- PV array's current/temperature constant: $6.41 \times 10^{-4} \mathrm{~A} / \mathrm{K}$

- AC frequency: $50 \mathrm{~Hz}$

The conditions gave the following Maximum Power Point (MPP) values, and the voltage $U_{M P P}$ is the set point of the voltage regulation.

- $U_{M P P}: 337.5 \mathrm{~V}$

- $I_{M P P}: 3.403 \mathrm{~A}$

- $P_{M P P}: 1149 \mathrm{~W}$

\section{B. Synoptic of Architecture}

Fig. 1 shows the architecture used to simulate the PV system. Table 1 describes the processes involved. 


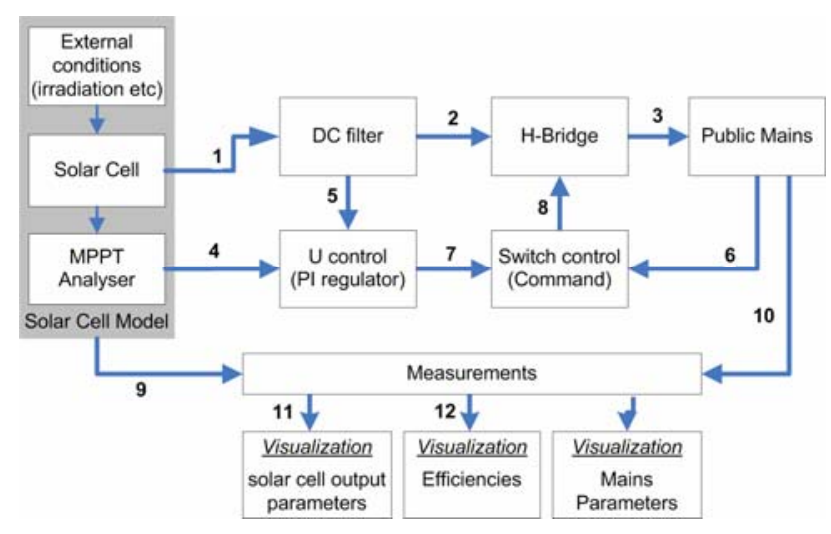

Fig. 1. Synoptic of architecture used to the PV system connected to the grid

TABLE I.

DESCRIPTION OF SIGNALS IN FIG. 1.

\begin{tabular}{|c|l|}
\hline Signal & Description \\
\hline 1 & DC voltage \& current from solar cells \\
\hline 2 & DC values from the DC filter \\
\hline 3 & AC output injected into the public mains \\
\hline 4 & $U_{\text {max }}$ is preprocessed by MPPT block within the PV model \\
\hline 5 & Filtered voltage is addressed on to the regulator \\
\hline 6 & Feedback from the mains to control switching (H-Bridge) \\
\hline 7 & Set-point RMS current value for switch controller to actuate \\
\hline 8 & Switch pulses (command values) \\
\hline $9 \sim 13$ & Measurements of various signals for visualization \\
\hline
\end{tabular}

As explained in the previous paragraph, the inverter topology is a transformerless single stage. The control scheme is based on PI regulation with bang-bang switching strategy. To reduce THD, a specific PI regulator is designed to verify the standards.

From the descriptive summary of signals flowing in Table I, it can be seen that the voltage control scheme has been used to determine the Maximum Power Point that must be delivered to the inverter for AC conversion. The mains current is controlled using the bang-bang switching strategy on a H-bridge inverter with respect to a reference voltage waveform.

The regulator and MPPT analyzer system is designed to be embedded in a high speed microcontroller or a Digital Signal Processor (DSP).

\section{Photovoltaic Module Modelling}

The PV module is designed using a combination of standard blocksets available in SimPowerSystem library and some functions are developed in $\mathrm{C}$ language.

Fig. 2 shows the realization of such a model. This one is an extended version of the basic PV solar cell taking into account the leakages in real cells [5], [12].

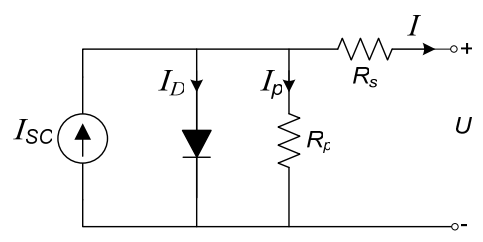

Fig. 2. Solar Cell Model.

The circuit Fig. 2 can be expressed mathematically as denoted in (1).

$$
I=I_{S C}-I_{0}\left(\exp \left[\frac{q\left(U+I \cdot R_{s}\right)}{k T}\right]-1\right)-\left(\frac{U+I \cdot R_{s}}{R_{p}}\right)
$$

Where $I, I_{S C}, I_{0}$, are respectively , the output current of the cell, cell short circuit current, reverse saturation voltage of the non-ideal diode. $U$ represents the final voltage of the PV cells, $T$, the junction temperature and, $R_{s}$ and $R_{p}$ are respectively series and parallel leakage resistances. Moreover, $\mathrm{q}$ is the electronic charge $q=1.6 \times 10^{-19} \mathrm{C}$ and k Boltzmann's constant $k=1.381 \times 10^{-23} \mathrm{~J} / \mathrm{K}$.

In our case, the cell junction temperature $T$ is fixed at $25^{\circ} \mathrm{C}$. Since (1) cannot be solved using direct evaluation, Newton approximation is applied to obtain output current.

To obtain a close representation of a real solar cell, the series and parallel resistances of the cells $R_{s}$ and $R_{p}$ respectively, were determined through experimental processes in PSpice. The expressions for the resistances were established with respect to the open loop voltage of the solar cell as given in (2) and (3).

$$
\begin{gathered}
R_{p}=620 \Omega+\left(1.066 \frac{\Omega}{V}\right) \cdot U_{S T C} \\
R_{s}=\left(0.073 \frac{\Omega}{V}\right) \cdot U_{S T C}
\end{gathered}
$$

where the values in parenthesis are Ohms/volt factor and $U_{\text {STC }}$ the cell output voltage under Standard Test Conditions (STC).

The Fill Factor (FF) of the cell given in (4) is also calculated in real time during processing to get an even closer representation of the solar cell.

$$
F F=\frac{P_{M P P T}}{U_{L} \cdot I_{K}}=\frac{U_{M P P T} \cdot I_{M P P T}}{U_{L} \cdot I_{K}}
$$

where $U_{L}$ and $I_{K}$ represents the open loop voltage and the short circuit current respectively, $U_{M P P T}$ and $I_{M P P T}$ represents the voltage and current respectively at which the maximum power $P_{M P P T}$ is produced by the cell.

\section{Maximum Power Point Tracking (MPPT)}

The PV modules have inherent nonlinear current versus voltage characteristics. Therefore it becomes necessary to track the point at which maximum power can be harnessed from the module. The maximum power occurs at the "knee" of the I-V characteristics as shown in Fig. 3. It must also be noted that the power profile is also nonlinear especially around the maximum level. Hence a straightforward mathematical analysis is not possible. A 
number of algorithms have been suggested in the literature [3]-[5], [11].

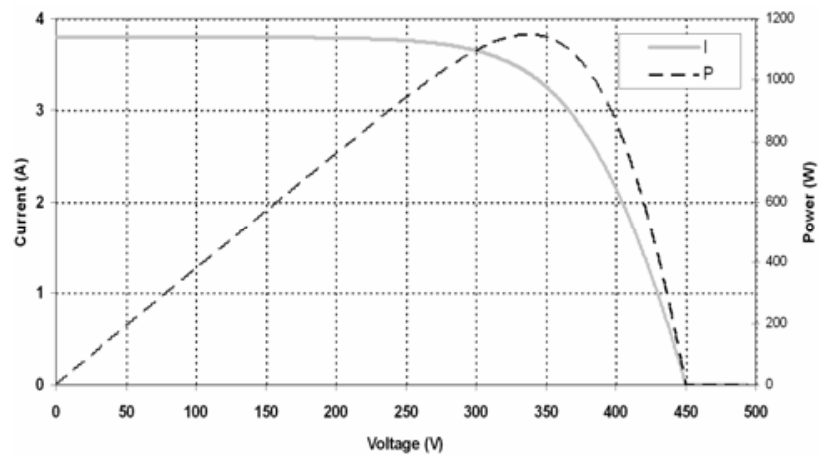

Fig. 3. Typical I-V Characteristics of PV modules

The MPPT algorithm is as simple as possible since it is not an objective to develop its effects and in our case it is more important to reduce simulation times and to avoid sudden convergence of the parameters in the model. Hence a C-scripted search algorithm is developed to perform search for the MPPT on the power curve. The MPPT values are then used to regulate the voltage with a PI regulator.

\section{E. DC Filter}

Due to nonlinear characteristics of the generated power from the PV module, variations in insulation, and most importantly the mains interference which generates a $100 \mathrm{~Hz}$ ripple in the module current, a DC filter is designed.

A higher $\left(3^{\text {rd }}\right)$ order filter is designed by combining a PI filter with as series inductance depicted in Fig. 4.

The filter has multiple functions, it delivers a highly filtered output power to the inverter and it also acts as energy storage. During one part of the H-Bridge switching interval, energy is sourced from the filter and the second part, the storage elements are charged again.

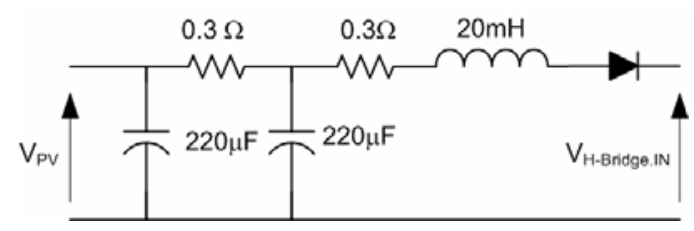

Fig. 4. Typical I-V characteristics of PV modules

\section{F. Inveter Topology and Public Mains simulations}

The topology under test is a transformerless, singlestage, H-bridge inverter directly coupled to the grid as shown in Fig. 5. One inherent attribute of H-Bridge topology which poses a major constraint is that a dead time has to be introduced so that the switches in one particular leg $\left(\left\{S_{1}\right.\right.$ and $\left.S_{2}\right\}$ or $\left\{S_{3}\right.$ and $\left.\left.S_{4}\right\}\right)$ are not in the ON state together at any given instant time as it may short circuit the DC supply. The size of this dead time normally depends on switching or command scheme used.

The impedance of public mains is typically operating at $50 \mathrm{~Hz}$ and with lagging power factor hence some typical values were obtained from [5], [14]. An inductor with $L=$ $0.05 H$ and a resistor fixed at $R=0.5 \Omega$ is used to simulate the public mains as indicated in Fig. 5.

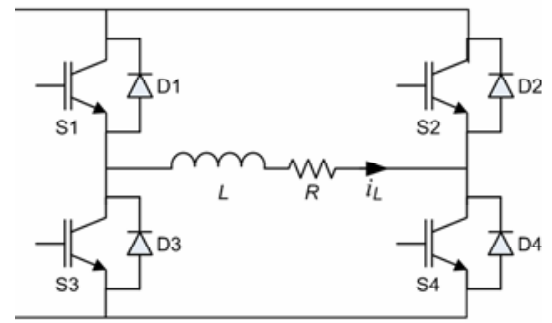

Fig. 5. H-Bridge topology

\section{G. Command Strategy}

The command strategy employed is known as bangbang control. In this strategy, the desired waveform is set as the control with upper \& lower boundary or set-points floating with it [15]. A switching pattern in Fig. 6 is generated for switches $S_{1}$ to $S_{4}$ in the H-bridge in Fig. 5 .

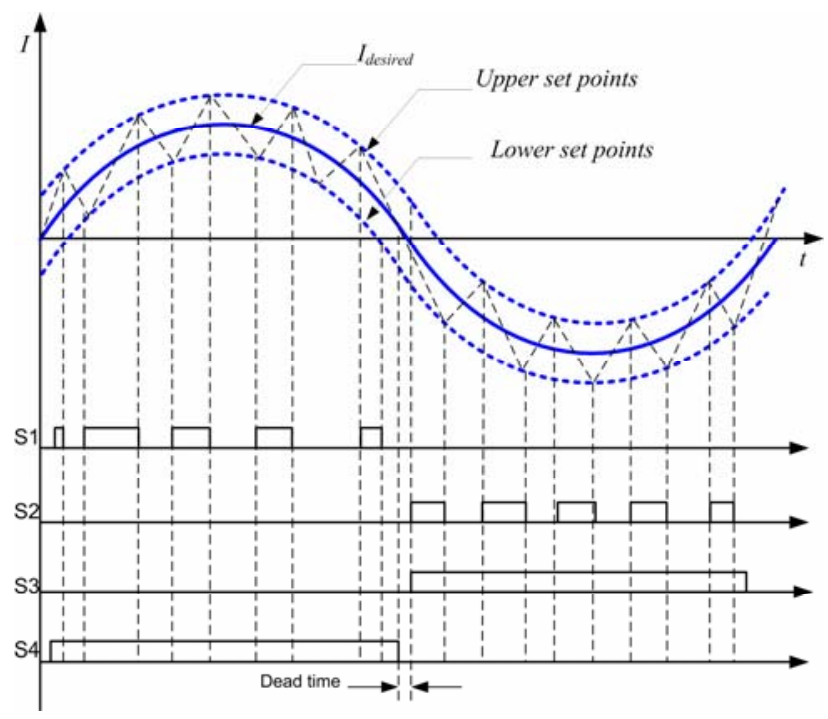

Fig. 6. Illustration of Bang-Bang command scheme [15]

Additional routines were developed in C language to add dead time and to ensure that short circuit conditions do not occur in the H-Bridge topology investigated.

A semiconductor (IGBT) switch is developed using ideal switch instead of using the IGBT blockset available in SimPowerSystem library, this was because the available IGBT in SimPowerSystem can not be simulated in discrete step time environment.

During the positive half cycle of sine wave, the output current is controlled using switches $S 1$ and $S 4$ in Fig. 6. For the negative half cycle commutation, $S 2$ and $S 3$ are used. The upper and lower set point boundary limits follow the same profile as the desired current waveform offset by a factor $\varepsilon$.

If the desired mains current is $i(t)=I_{\max } \sin (\omega t)$ then the boundary limits are

$$
i(t)=I_{\max } \sin (\omega t) \pm \varepsilon
$$

Where $\varepsilon$ depends on switching frequency of the inverter.

In the process, $\varepsilon=0.05 \mathrm{~A}$ and a dead time is introduced every time the sine wave crosses the time or the $\mathrm{x}$-axis. This model is subjected to THD regulation to increase the efficiency of the PV system. 


\section{H. Regulator}

The output voltage without filter has a variation of $17 \mathrm{~V}$ with a frequency of $100 \mathrm{~Hz}$. A filter depicted in (6) is designed with a cut-off frequency of $10 \mathrm{~Hz}$, selected as a trade-off between system speed and desired level of filtering.

$$
F(s)=\frac{1}{(1+0.01 s)}
$$

The set points created by the filter are used to regulate switching to accomplish the inverter output within the threshold stipulated by the relevant standards [6]-[8]. The switching regulation is achieved by employing a proportional integrate (PI) regulator. The regulator developed in (7) has a bandwidth of $0.023 \mathrm{~s}$ and the integrator time constant $T_{n}=0.031 \mathrm{~s}$.

$$
F(s)=k_{p} \frac{T_{n} s+1}{T_{n} s}=27.74 \frac{0.031 s+1}{s}
$$

In addition to this configuration, a THD regulator is designed to keep this parameter within bounds of less than 5\% according to [7], [8]. a PI regulator is adopted as depicted in (8). Since the inverter's dead (switching changeover) time is high (due to H-Bridge configuration), the time constant for the regulator is set to $0.05 \mathrm{~s}$ for closed loop.

$$
F(s)=0.4 \frac{0.2 s+1}{s}
$$

\section{Simulation RESUltS}

The simulations are performed with Matlab. To ensure that the computer does not induce any interference to the simulation process, all irrelevant processes were stopped.

Results are shown on Fig. 7. The harmonics is evaluated using the built-in function of SimPowerSystem which easily generates the harmonics report from the output current waveform.

The single-stage self-commutated H-bridge inverter designed clearly meets all standards requirements for grid connection. Fig. 7(c) shows the harmonics up to order $400^{\text {th }}$ (with fundamental frequency equal to $50 \mathrm{~Hz}$ ).

Using the PI regulator, two main processes were established simultaneously by using the H-Bridge; harnessing maximum power from the PV module through the DC filter with setpoints created by MPPT algorithm, and generating the mains current and voltage waveform at the mains frequency.

The main switch command (PI) and the sub regulator, the THD regulator is designed using system's step response and does not consider the transient behavior.

As it can be seen in Fig. 7(b), the zero-crossing contributed to an increase in THD. This zero-crossing distortion is mainly due to dead time when all switches in the $\mathrm{H}$-Bridge are off (dead-time). Introducing THD, PI regulator decreased the THD only by $0.5 \%$ but DC component also reduced quite significantly to $0.15 \%$. In comparison to the standard particularly IEC 6172, which regulates inverters with power up to $10 \mathrm{~kW}$, the maximum current THD allowed to be injected into the mains is 5\% and DC injection must be less than $1 \%$. Thus, the inverter meets these minimum standards fairly well.

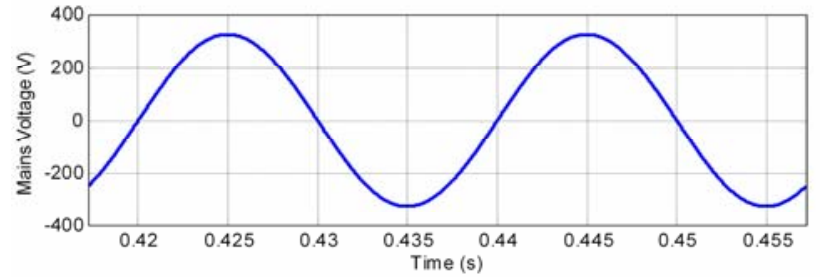

(a)

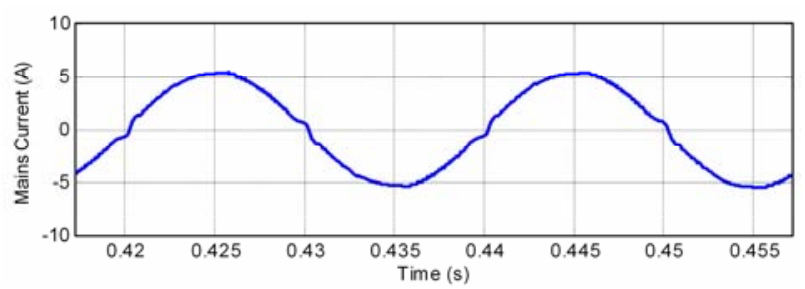

(b)

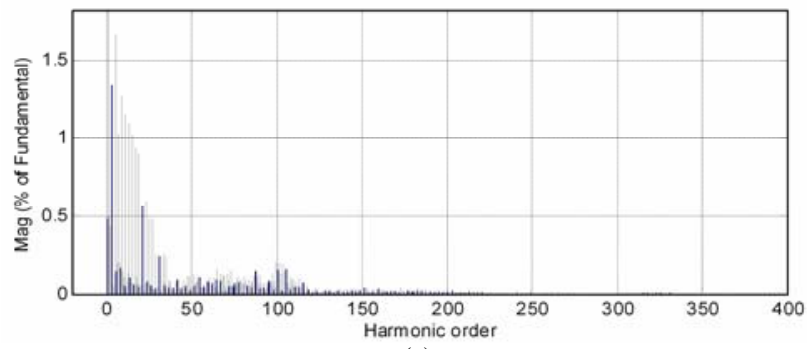

(c)

Fig. 7. Simulation Results of Bang-bang control strategy - (a) Voltage (reference), (b) current, (c) Harmonics in current

TABLE II.

SUMMARY OF SIMULATED RESULTS.

\begin{tabular}{|l|l|}
\hline Characteristic & Results \\
\hline Solar Cell Efficiency $\left(\eta_{\text {Solar }}=P_{A C} / P_{D C}\right)$ & $11.49 \%$ \\
\hline Inverter Efficiency $\left(\eta_{\text {Inverter }}=P_{A C} / P_{D C}\right)$ & $95 \%$ \\
\hline Adaptation Efficiency $\left(\eta_{\text {Adapt }}=P_{D C} / P_{\text {Max.DC }}\right)$ & $99 \%$ \\
\hline Static efficiency $\left(\eta_{\text {Static }}=\eta_{\text {Inverter }} \cdot \eta_{\text {Adapt }}\right)$ & $94 \%$ \\
\hline Total system efficiency $\left(\eta_{\text {System }}=\eta_{\text {Solar }} \cdot \eta_{\text {Static }}\right)$ & $10.8 \%$ \\
\hline THD & $3.80 \%$ \\
\hline DC component & $0.15 \%$ \\
\hline Transient time & $0.075 \mathrm{~s}$ \\
\hline Mains Voltage (rms) & $230 \mathrm{~V}$ \\
\hline Mains Current (rms) & $3.78 \mathrm{~A}$ \\
\hline Simulation Time step & $10 \mu \mathrm{s}$. \\
\hline Simulation Time & $10 \mathrm{~s}$ \\
\hline
\end{tabular}

Overall, the system performed quite well in all areas as summarized in Table II. The crystalline silicon PV module has efficiencies typically comprise between $9-13.5 \%$ and comparative inverters in the market have efficiencies over $90 \%$ according to [11]. 


\section{CONCLUSION}

With future outlook for PV systems connected to the grid, it has become necessary to improve the efficiency and the quality of power produced by them. Particularly, the inverter which is the main component for producing the AC signals must be well designed; a high efficiency, a clean signal (harmonics at lowest) and DC components are required to attends standards.

In this paper, a single stage $\mathrm{H}$-Bridge inverter is designed. The full grid connected PV system is simulated to study the effect of bang-bang switching command on the mains power, particularly focusing on the current. All real life parameters like switching, dead time, insulations conditions and grid influences have been taken into account.

Notwithstanding of losses in components, results show that the inverter designed meets all relevant standards requirements. The PI regulators works fairly well at the maximum irradiation of $1000 \mathrm{~W} / \mathrm{m}^{2}$. Like many controllers for other physical systems, it is possible now to simulate fairly accurately the performance of a model PV inverter in a software PV model before going on to realize the actual device for further analysis of component loss etc. With rapid development process, this inverter is fully realized as software model first to study the effect of topology selected for the system.

The limitations of simulator package and speed of simulating computer plays vital role on simulated results. Generally a dedicated high speed workstation is necessary but the several runs on the standard portable computer conforms that no errors were induces by sudden convergence of high order ODE solvers used by Matlab.

\section{REFERENCES}

[1] Photovoltaic/thermal Solar Energy Systems - Status of the Technology and roadmap for Future Development, Report IEA PVPS T7-10, 2002

[2] J. P. Benner, L. Kazmenki 'Photovoltaics gaining greater visibility’, IEEE Spectrum, vol. 29, issue 9, pp. 3442, 1999.

[3] D. Crue Martins, R. Demonti, R. Ruther, “Analysis of Utility Interactive Photovoltaic Generation System Using A Single Power Static Inverter”, Proceedings of Photovoltaic Specialists Conference, Sept. 2000, pp. 1719-1722.

[4] M. Yamaguchi, K. Kawarabayashi and T. Takuma, "Development of A New Utility-Connected Photovoltaic Inverter Line Back," Proceedings of INTELEC'94, pp. 676-682.

[5] DGS (Deutsche Gesellschaft für Solarenergie) : Photovoltaische Anlagen, 2nd edition, Geisel Druck Berlin, Berlin 2002

[6] Limits for Harmonic Current Emission (Equipment Input Current $<16$ A per Phase), EN 61000-3-2, 1995.

[7] Characteristics of the Utility Interface for Photovoltaic (PV) systems, IEC 61727 CDV (Committee Draft for Vote), 2002.

[8] IEEE Standard for Interconnecting Distributed ResourcesWith Electric Power Systems, IEEE Std. 1547, 2003.

[9] F. Blaabjerg, Z. Chen, and S. B. Kjaer, "Power Electronics as Efficient Interface in Dispersed Power Generation Systems”IEEE Transc. on Power Electronics, Vol 19, No.5 , Sept. 2004, pp 11841194

[10] K. Ogura, S. Chandhaket, Y. Hirota, E. Hiraki, M. Nakaoka, "Small Scale Utility-Connected Solar Photovoltaic Power Conditioner using Soft Switching High-Frequency Sinewave Modulated Inverter Link for Residential Applications” Mem of Faculty of Engineering, Yamaguchi University, Vol. 52, No 2., 2002, pp. 95-100

[11] G. M. Masters, Renewable and Efficient Electric Power Systems, Wiley, New Jersey, 2004, pp 386-405.
[12] N. Mohan, T. Underland, W. Robbins, Power Electronics Converters, Applications and Design, $3^{\text {rd }}$ Ed, Wiley, New York, 2003, Ch. 8-11.

[13] D. Ton, W. Dower, "Summary Report on the DOE High-tech Inverter Workshop”, Jan, 2005.

[14] A. V. Timbus, R. Teodorescu, F. Blaabjerg, and U. Borup, "Online Grid Measurement and ENS Detection for PV Inverter Running on Highly Inductive Grid”, IEEE Power Electronics Letters, Vol. 2, No. 3, Sept. 2004, pp 77-82.

[15] G. Hagmann, Leistungselektronik, $2^{\text {nd }}$ ed, Aula Verlag, Wiesbaden 1998. 